\title{
Questions and commentary on the article 'Daily changes of peak expiratory flow and respiratory symptom occurrence around a soy processing factory'
}

\author{
Tomasz Targowski ${ }^{1}$ \\ ${ }^{1}$ Department of Internal Medicine, Pneumonology and Allergology, Military Institute of Medicine, Warsaw, Poland
}

\section{Dear Editor,}

An interesting article by Heederik D et al. was published in a recent number of Ann Agric Environ Med. (2014, vol. 21, no $1,5-10)$ concerning the relationship between, on the one hand, concentration of soy allergens in the proximity of a factory producing soy oil and intensity of respiratory symptoms, daily changes of peak expiratory flow (PEF) and bronchodilator utilization [1]. The authors tested daily changes of PEF, bronchodilator use and respiratory symptoms in two groups of people: those living in the vicinity of the soy oil factory and habitants living in the control area located about $5 \mathrm{~km}$ from the factory. They found positive skin prick tests (SPTs) to common allergens among $81 \%$ of participants and positive results of SPTs to soy in $11-12 \%$ examined people. The authors concluded that sensitization to soy allergen was not increased among the people living in the proximity of the factory; however, the soy-sensitized individuals living in the surroundings of the factory reported more respiratory symptoms, greater bronchodilator utilization, and lower PEF after having been downwind of the factory. Peak expiratory flow measurements, above all, are a useful method of evaluation of asthma control. Daily variability of PEF of more than $20 \%$ can be a symptom of pathological bronchial tree hyperresponsiveness (BHR) and bad asthma control [2]. BHR is an individual feature and is not directly correlated with the concentration of aeroallergens. Among people with allergic rhinoconjunctivitis and without bronchial asthma and/or BHR, the daily variability of PEF could be slight and may be comprised in the normal value for healthy people. The authors found positive results of allergic skin prick tests in the majority of participants from both groups (81\%). Unfortunately, they did not report the percentage of people with asthma in both groups. This is important information, insofar as, for example, a higher incidence of bronchial asthma and BHR among participants from the study group may have influence on the greater variability of PEF, respiratory symptoms and bronchodilator consumption. Additionally, on the other hand, the lack of people with bronchial asthma in the control group could result in small daily PEF changes, scant other symptoms.

It is also worth considering the smoking status of the participants in the statistical analysis. In the study group, the percentage of current smokers was higher than in the control; obviously, tobacco addiction has a significant influence on bronchial hyperresponsiveness and value of spirometric function tests [3].

\section{REFERENCES}

1. Heederik D, Van Strien R, Doekes G, Brunekreef B. Daily changes of peak expiratory flow and respiratory symptom occurrence around a soy processing factory. Ann Agric Environ Med. 2014; 21(1): 5-10.

2. The Global Initiative for Asthma (GINA), May 2014 http://www. ginasthma.org (access: 2014.07.14).

3. Rosewich M, Schulze J, Eickmeier O, Adler S, Rose MA, Schubert R, et al. Early impact of smoking on lung function, health, and well-being in adolescents. Pediatr Pulmonol. 2012; 47(7): 692-699. 